\title{
INTRAPULMONARY INTERLEUKIN 1 MEDIATES ACUTE IMMUNE COMPLEX ALVEOLITIS IN THE RAT
}

\author{
Jeffrey S. Warren \\ Department of Pathology, The University of Michigan Medical School \\ 1301 Catherine Street, Ann Arbor, MI 48109-0602
}

Received January 31, 1991

Interleukin $1 \alpha$ and $\beta$ are polypeptide cytokines that possesses a wide variety of immunologic and inflammatory activities. We have examined the role of intrapulmonary interleukin 1 in the pathogenesis of acute IgG immune complex alveolitis in the rat. Intratracheal instillation of IgG anti-bovine serum albumin accompanied by intravenous infusion of bovine albumin results in acute neutrophil and complement-dependent alveolitis. Over the course of evolving lung injury there was a 12-fold increase in bronchoalveolar lavage fluid interleukin 1 activity. Intratracheal instillation of neutralizing anti-interleukin $1 \beta$ antibodies upon induction of lung injury resulted in a dose-dependent reduction in lung injury as assessed by measurements of pulmonary hemorrhage and vascular permeability. Morphometric analysis and measurements of myeloperoxidase activities in whole lung homogenates from rats that received anti-interleukin $1 \beta$ revealed a pronounced reduction in neutrophil recruitment compared to positive controls. Incubation of isolated alveolar macrophages with preformed IgG immune complexes resulted in dose-dependent interleukin 1 secretion. These data suggest that intrapulmonary $\mathrm{IL}-1$ activity plays a role in neutrophil recruitment and is necessary for the full development of acute IgG immune complex induced lung injury in the rat. $\theta 1991$ Academic

Press, Inc.

Interleukin 1 has been implicated in a variety of immunologic and inflammatory processes (1, reviewed). Interleukin 1-like activity has been recovered from a variety of inflamed tissues (2-6). Inoculation of highly purified or recombinant human IL-1 into the joints, skin, or eyes of experimental animals promotes localized acute inflammatory changes (7-9). In vitro studies indicate that IL-1 induces the upregulation of leukocyte adhesion molecules by several cell types, including endothelial cells (10-14). Exposure of endothelial cell monolayers to IL-1 also results in the secretion of soluble inflammatory mediators including neutrophil chemotactic factor and monocyte chemoattractant protein-1 $(15,16)$.

Interleukin $1 \alpha$ and $\beta$ are biochemically distinct, separately encoded molecules thought to be derived from a common ancestral gene $(17,18)$. Interleukin $1 \beta$ predominates in the circulation and other body fluids and is presently thought to be the more prevalent soluble form of this cytokine (1). A homologous region of IL-1 $\alpha$ and $I L-1 \beta$, termed C-D, is the minimal

\footnotetext{
ABBREVIATIONS

IL-1, interleukin 1; BSA, bovine serum albumin; BAL, bronchoalveolar lavage; TNF, tumor necrosis factor; PBS, phosphate buffered saline; MPO, myeloperoxidase; HPF, high power field; RBC, red blood cells; SEM, standard error of the mean; FBS, fetal bovine serum.
} 
recognition site for IL-1 receptors (1). Receptors for $\mathrm{IL}-1$ equally bind the $\alpha$ and $\beta$ forms, both of which exhibit the same biological activities (1).

In the present study we have analyzed the role of intrapulmonary IL- 1 in the pathogenesis of acute IgG immune complex alveolitis in the rat. The results of this study indicate that locally produced IL-1 mediates acute immune complex-triggered alveolitis through a mechanism involving pulmonary neutrophil recruitment.

\section{MATERIALS AND METHODS}

Animal Model of Immune Complex Alveolitis. Male Long-Evans specific pathogen free rats (350 g; Charles River Breeding Laboratories, Inc., Wilmington, MA) were used for all studies. Intraperitoneal injections of ketamine $(2.5-5.0 \mathrm{mg} / 100 \mathrm{~g}$ body $w \mathrm{t})$ and sodium pentobarbital $(5 \mathrm{mg} / 100 \mathrm{~g}$ body wt) were given for sedation and anesthesia. Immune complex lung injury was induced as previously described (19). Antibody solutions (250 $\mu \mathrm{g}$ anti-BSA unless otherwise specified) were instilled into the lungs via a tracheal cannula. Antigen (BSA, $10 \mathrm{mg}$ ) was injected intravenously. Rats were sacrificed at the indicated times and BAL fluid harvested (see below) or lung injury quantitated. Pulmonary injury was quantitated by permeability measurements as well as by morphometric analysis $(19,20)$.

Collection of BAL Fluid and Isolation of Alveolar Macrophages. Alveolar macrophages and bronchoalveolar lavage fluid were recovered as previously described (20). At least $90 \%$ of the administered fluid ( $5 \mathrm{ml}$ ) was always recovered, centrifuged $(400 \mathrm{~g} ; 7 \mathrm{~min})$ to remove cells, and stored at $-20^{\circ} \mathrm{C}$ until analysis.

Morphometric Analysis of Lung Injury. Transmission electron micrographs were prepared from whole lungs fixed in $4 \%$ glutaraldehyde under constant pressure inflation $(25 \mathrm{~cm}$ $\mathrm{H}_{2} \mathrm{O}$ ), washed in $0.1 \mathrm{M}$ cacodylate buffer $(\mathrm{pH} 7.3)$, and embedded in plastic. 1- $\mu \mathrm{m}$-thick sections were stained with toluidine blue and processed for transmission electron microscopy by using a 401 transmission electron microscope (401; Philips Electronic Instruments, Mahwah, NJ). As previously described, morphometric analysis was carried out by experienced electron microscopist (R.G. Kunkel) who was blinded to sample origin (20). For each condition five lung samples were examined. In each sample, 45-60 randomly selected 40x microscopic fields were analyzed.

Preparation of IgG anti-BSA. Rabbit IgG rich in antibody directed against BSA was used to induce lung injury and to form precipitating IgG-BSA immune complexes. Antibody content and production of immune complexes have been previously described in detail (19). The IgG anti-BSA and BSA (low endotoxin; ICN Biomedicals, Costa Mesa, CA) preparations contained $<0.02 \mathrm{ng} / \mathrm{ml}$ and $0.012 \mathrm{ng} / \mathrm{ml}$ of endotoxin activity, respectively, as estimated using the Limulus amebocyte lysate assay (E-toxate; Sigma Chemical Co., St. Louis, MO). Antigen-antibody equivalence for these reagents has previously been shown to occur at 1:5 (wt/wt) ratio (19).

Preparation of TNF and IL-1-rich Conditioned Medium from Alveolar Macrophages. Rat alveolar macrophages were suspended in RPMI 1640 (KC Biological, Lenexa, KS), supplemented with $100 \mathrm{U} / \mathrm{ml}$ penicillin, $100 \mu \mathrm{g} / \mathrm{ml}$ streptomycin, $300 \mu \mathrm{g} / \mathrm{ml}$ fresh glutamine, and $10 \%$ heat-inactivated fetal calf serum (FCS; Gibco Laboratories, Grand Island, NY). Alveolar macrophages $(2 \times 10 \%$ ml) were plated in $35 \mathrm{~mm}$ polystyrene dishes (Corning Glass Works, Corning, NY) and maintained in a humidified $5 \% \mathrm{CO}_{2}$ atmosphere at $37^{\circ} \mathrm{C}$ to allow macrophages to adhere. After $2 \mathrm{~h}$, the dishes were gently washed twice with serum-free $37^{\circ} \mathrm{C}$ RPMI 1640 and Escherichia coli lipopolysaccharide 0111:B4 (Sigma Chemical Co.) $(10 \mu \mathrm{g} / \mathrm{ml}$ ) was added to culture dishes. The dishes were maintained for $4 \mathrm{~h}$ in serum-free RPMI under the same conditions as above. After the incubation period, supernatants were collected, and aliquots assayed for IL-1 and TNF activity.

IL-1 assay. IL-1 levels were measured by means of thymocyte coproliferation assay, as modified from the procedure of Mizel et. al. (21). Briefly, 5 x $10^{5}$ murine (C3H/HeJ) thymocytes in $0.1 \mathrm{ml}$ of complete RPMI 1640 containing $2.5 \mu \mathrm{g} / \mathrm{ml}$ of phytohemagglutinin (Burroughs Welcome, Research Triangle Park, NC) were added to each well of a 96-well 
microtiter plate. Equal volumes of $\log _{2}$ dilutions of sample were added to the wells in triplicate. After $66 \mathrm{~h}$ incubation at $37^{\circ} \mathrm{C}$ in $5 \% \mathrm{CO}_{2} / 95 \%$ air, the thymocytes were pulsed with $0.5 \mu \mathrm{Ci}$ $\left[{ }^{3} \mathrm{H}\right]$ thymidine $(6.9 \mathrm{Ci} / \mathrm{nmol}$; ICN Nutritional Biochemicals, Irvine, CA) and collected $6 \mathrm{~h}$ later on glass fiber strips using an automatic cell harvester. $\left[{ }^{3} \mathrm{H}\right]$ Thymidine incorporation was determined by using a liquid scintillation counter. For standardization, data are expressed as units/ml based on a recombinant human IL-1 $\beta$ standard (The Upjohn Co. Kalamazoo, MI) assayed concomitantly with unknown samples.

TNF Assay. TNF activity was measured by means of modification of the procedure of Ruff and Gifford (22). Briefly, equal volumes of $\log _{2}$ dilutions (final volume $0.1 \mathrm{ml}$ ) of samplecontaining media were made in 96-well microtiter plates (Costar, Cambridge, MA) containing target LM cells (mouse fibroplast cell line derived from NCTC clone 929; American Type Culture Collection) $\left(5 \times 10^{4}\right.$ cells per $0.1 \mathrm{ml}$ ) in the presence of actinomycin $\mathrm{D}$ (final concentration, $1 \mu \mathrm{g} / \mathrm{ml})$. In a separate set of wells, a standard consisting of serially diluted recombinant human TNF (Cetus Immune Laboratories, Palo Alto, CA) was added. The cells were incubated at $37^{\circ} \mathrm{C}$ for $18 \mathrm{~h}$, the supernatants discarded, and the remaining viable adherent cells washed with PBS and then stained by adding crystal violet $(0.2 \%$ in $2 \%$ ethanol) for 5 min. Microtiter plates were rinsed three times with PBS and allowed to air dry. The absorbance of each well was read at $620 \mathrm{~nm}$ with a MicroELISA Autoreader (BioTek Instruments, Winooski, VT). Units of TNF are defined as the reciprocal of the dilution at which $50 \%$ cytolysis occurs.

Preparation of IgG anti-IL-1 $\beta$ Antibodies. Anti-IL-1 $\beta$ was produced by immunization of rabbits with recombinant murine $\mathbb{I}-1 \beta$ (Genzyme, Boston, MA). The resulting antiserum was affinity purified using a protein A Sepharose column (Sigma). Anti-IL-1 serum was diluted 1:1 with PBS (100 mM phosphate, pH 8.0, $150 \mathrm{mM} \mathrm{NaCl}$ ) and applied slowly to the PBS-washed column. After extensive washing with PBS, the column was stripped with $100 \mathrm{mM}$ sodium acetate buffer, $\mathrm{pH} 3.0$ Fractions $(1 \mathrm{ml})$ were collected in tubes containing $50 \mu \mathrm{l}$ of $1 \mathrm{M}$ Tris buffer, $\mathrm{pH}$ 8.0. The affinity purified IgG fraction was then dialyzed against PBS and tested for specificity against IL-1.

Whole Lung Myeloperoxidase Activities. Pulmonary neutrophil recruitment was quantitated by measuring whole lung myeloperoxidase as previously described (23). Whole lungs were homogenized with a Polytron homogenizer $(4 \times 10$ s at a setting of 4$)$ using $6 \mathrm{ml}$ of homogenization buffer. The homogenization buffer $(50 \mathrm{mM}$ phosphate, $\mathrm{pH} 6.0)$ contained $0.5 \%$ hexadecyltrimethyl ammonium bromide (Sigma) and $5 \mathrm{mM}$ EDTA. Homogenized samples were then sonicated $(3 \times 10 \mathrm{~s}$ at a setting of 5$)$ and centrifuged $(3,000 \times \mathrm{g} ; 30 \mathrm{~min})$ at $4^{\circ} \mathrm{C}$. Myeloperoxidase activity in supernatants was assayed by measuring the change in $\mathrm{A}_{460}$ resulting from decomposition of $\mathrm{H}_{2} \mathrm{O}_{2}$ in the presence of o-dianisidine (24).

\section{RESULTS}

Elaboration of Intrapulmonary L-1 During IgG Immune Complex Induced Lung Iniury. Bronchoalveolar lavage fluids were examined for the presence of $\mathrm{IL}-1$ as a function of time after airway instillation of anti-BSA and intravenous infusion of BSA. A modest increase in IL-1 activity could be detected in the first two hours (Figure 1). After 2 hrs. there was a rapid rise in BAL IL-1 activity; by $4 \mathrm{hrs}$. IL-1 levels had increased 12-fold. In rats that received anti-BSA in the absence of antigen or heat denatured anti-BSA in the presence of antigen, the BAL fluid at 4 hrs. contained less than 5 units $/ \mathrm{ml}$ of $\mathbb{L}-1$. These data suggest that endotoxin contamination of the anti-BSA or BSA is not responsible for eliciting BAL fluid IL-1 and that the intrapulmonary elaboration of IL-1 is dependent on pulmonary immune complex formation.

In Vitro Production of IL-1 by Rat Alveolar Macrophages. Incubation of isolated alveolar macrophages with increasing concentrations of IgG:BSA immune complexes resulted in dosedependent release of IL-1 activity (Figure 2). Incubation of macrophages with IgG alone or BSA alone resulted in minimal $I L-1$ release, suggesting that $I L-1$ secretion is dependent on the presence of intact immune complexes. 

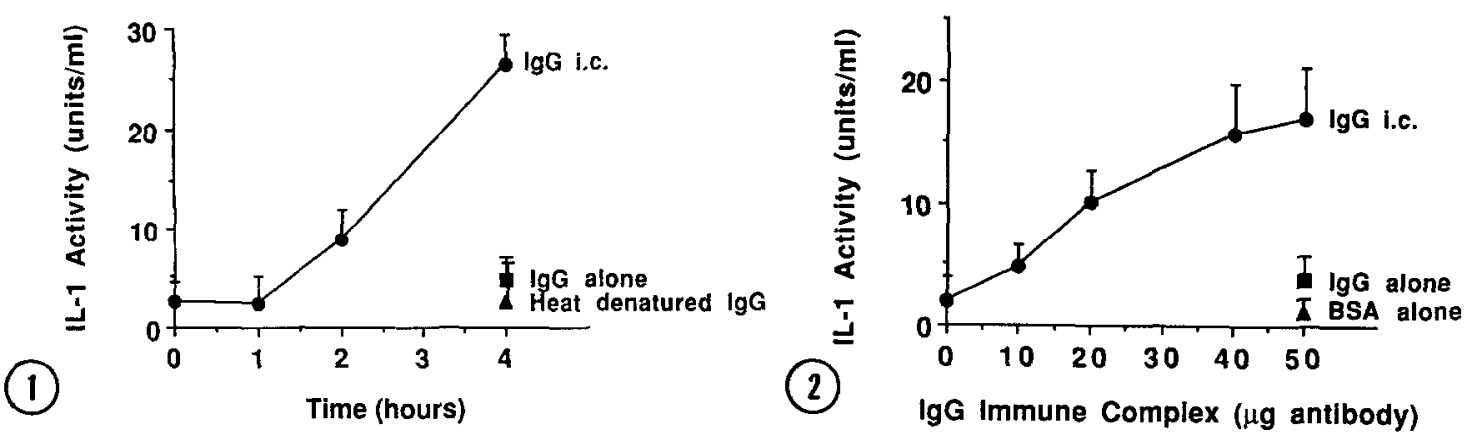

Figure 1. Elaboration of intrapulmonary (BAL fluid) IL-1 during the evolution of IgG immune complex lung injury. The data expressed represent the means \pm SEM of three experiments in which three to five rats were employed for each variable. Data were analyzed by one-way analysis with significance assigned for $p<.05(28) . *$ Indicates significant differences versus injured rats of time zero and negative control rats.

Figure 2. Preformed IgG:BSA immune complexes trigger IL-1 release by isolated alveolar macrophages. Alveolar macrophages suspended in RPMI 1640 with $10 \%$ heatinactivated FBS were allowed to adhere to polystyrene culture dishes $\left(2 \times 10^{6} / 35 \mathrm{~mm}\right.$ dish), washed, and incubated for $4 \mathrm{hrs}$. in serum-free RPMI $1640(2 \mathrm{ml})$ containing the indicated quantity of immune complex, IgG alone or BSA alone. The data represent the means \pm SEM of two experiments in which triplicate determination were made. All values are normalized for adherent cell number.

In Vitre Neutralization of Rat $\mathbb{I L}-1$ Activity with Specific Anti-li-1 1 _Antibodies. Aliquots of serum-free IL-1 and TNF-rich conditioned media from rat alveolar macrophage cultures were used to test the neutralizing capacity of the anti-IL-1 $\beta$ antibody and to verify the absence of cross reactivity with another relevant cytokine, TNF. Affinity purified IgG anti-IL$1 \beta$ antibodies blocked IL-1 activity in a dose dependent manner (Figure 3). Equivalent concentrations of irrelevant affinity purified rabbit IgG had no neutralizing effect on IL-1 activity. Even at concentrations of $100 \mu \mathrm{g} / \mathrm{ml}$, neither anti-IL-1 $\beta$ nor irrelevant rabbit IgG had significant blocking effects on TNF activity (114 units/ml) present in the conditioned medium (data not shown).

Blockade of IgG Immune Complex Alveolitis with Anti-IL-1ß Antibodies. Intratracheal instillation of anti-IL-1 $\beta$ resulted in a $58 \%$ reduction in IgG immune complex induced lung injury as assessed by measurements of pulmonary vascular permeability and hemorrhage (Table

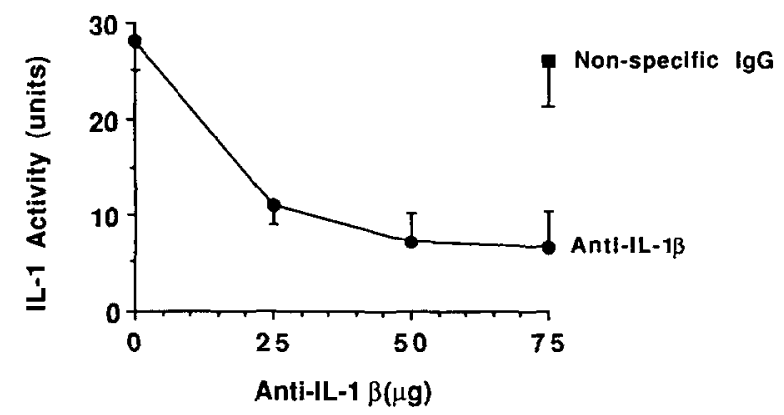

Figure 3. In vitro neutralization of IL-1 activity with anti-IL-1 $\beta$. Rat IL-1 (and TNF) activity was assayed from serum-free conditioned medium obtained from lipopolysaccharidestimulated rat alveolar macrophages. The data represent the means \pm SEM of two experiments in which each variable was assayed in triplicate. A common stock of conditioned medium was used for each experiment. 
Table 1. Blockade of IgG Immune Complex Lung Injury and Neutrophil Influx with Anti-IL-1B Antibodies

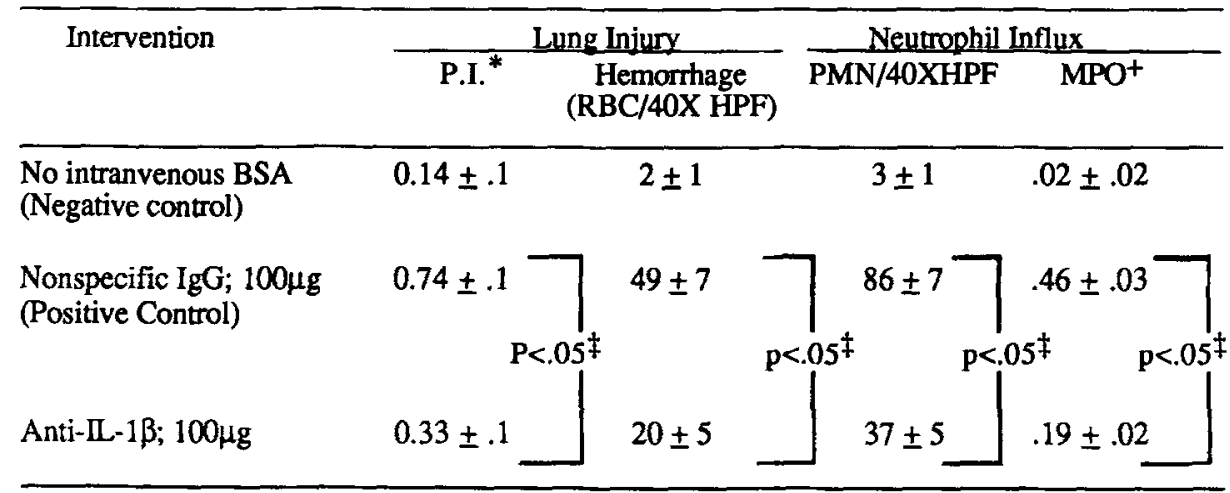

*Permeability index (see Materials and Methods).

+ Myeloperoxidase activity (whole lung homogenates) is expressed as $\Delta$ O.D. (A460) per minute resulting from decomposition of $\mathrm{H}_{2} \mathrm{O}_{2}$ in presence of o-dianisidine (24).

‡Data were analyzed by one-way analysis of variance (28).

1). Substitution of equivalent concentrations of heat inactivated anti-IL-1 $\beta$ (data not shown) or nonspecific rabbit IgG (Table 1) failed to suppress immune complex lung injury. In order to confirm that intratracheal instillation of anti- $\mathbb{L}-1 \beta$ reduced intraapulmonary $\mathbb{I L}-1$ activity, we measured BAL fluid IL-1 activity $4 \mathrm{hrs}$. after lung injury was induced. Bronchoalveolar lavage fluid from possitive control rats contained $26 \pm 3$ units/ml of IL-1 activity while rats that received anti-IL-1 $\beta$ contained $7 \pm 3$ units/ml of $\mathbb{\Pi L}-1$ activity.

Evidence that IL-1B_Contributes to Lung Injury Through a Neutrophil Mediated Mechanism. Morphometric analysis of lung sections confirmed that there was diminished neutrophil influx into the lungs of rats treated with anti-IL-1 $\beta$ compared to positive controls (Table 1). Myeloperoxidase measurements from whole rat lungs obtained from each of the treatment groups confirmed that there was a marked reduction of myeloperoxidase activity in the lungs of rats treated with anti-IL-1 $\beta$ antibodies compared to positive control rats (Table 1). These data suggest that $\mathbb{L}-1 \beta$ is necessary for the maximum recruitment of neutrophils into the lungs of animals with developing immune complex alveolitis.

\section{DISCUSSION}

A variety of proinflammatory activities have been attributed to IL-1 (1). Data derived from this study suggest that intrapulmonary IL-1 mediates acute immune complex alveolitis through a mechanism involving neutrophil recruitment. We have previously demonstrated an analogous role for TNF in the pathogenesis of acute alvcolitis (20). Several points should be addressed. Anti-IL-1 $\beta$ does not completely neutralize IL-1 activity, either in isolated alveolar macrophage supernatants, or retrieved BAL fluid from rats with evolving lung injury. This may be attributable to incomplete neutralizing capacity of anti-IL-1 $\beta$ and/or the presence of non-cross reacting IL-1 $\alpha$. While several studies suggest that $\mathbb{L}-1 \beta$ predominates over $\mathbb{L}-1 \alpha$ in bodily fluids, the relative proportions of $\mathbb{L}-1 \alpha$ and $\mathbb{L}-1 \beta$ in rat $B A L$ are unknown. In addition, the role of cell-associated IL-1 (presumed to the predominantly $\mathbb{L}-1 \alpha$ ) in acute alveolitis is unclear. 
Several IL-1-dependent pathways of neutrophil recruitment could be operative in this model. In vitro studies indicate that IL-1 can trigger platelet-activating factor and neutrophil chemotactic factor production by cells indigenous to the lung $(15,25)$. Interleukin-1 can also trigger the expression of endothelium-leukocyte adhesion molecule-1 by endothelial cells (13). All of these mediators could conceivably participate in the pathogenesis of acute immune complex alveolitis. The role of $\mathbb{I L}-1$ may be direct and/or indirect. For instance, local $\mathbb{L}-1$ production may regulate TNF secretion (or vice versa) $(26,27)$. Additional studies will be required to elucidate the complex relationships that exist among such inflammatory mediator systems.

\section{ACKNOWLEDGMENTS}

This work was supported by the National Institutes of Health grant HL-40526. The author wishes to thank Karen R. Yabroff for technical assistance, Robin G. Kunkel for morphometric analysis and graphics, and Kimberly D. Drake for manuscript preparation.

\section{REFERENCES}

1. Dinarello, C.A. (1988) FASEB J. 2, 108-115.

2. Wood, D.D., Ihrie, E.J., Dinarello, C.A., and Cohen, P.L. (1983) Arthritis Rheum. 26, 975-983.

3. Fontana, A., Hengartner, H., Weber, E., Fehr, K., Grob, P.J., and Cohen, G. (1982) Rheumatol Int. 2, 49-53.

4. McCracken, G.W., Mustafa, M.M., Ramilo, O., Olsen, K.D., and Risser, R.C. (1989) Ped. Infect. Dis. J. 8, 155-159.

5. Charon, J.A., Luger, T.A., Mergenhagen, S.E., and Oppenhein, J.J. (1982) Infection and Immunity 38, 1190-1195.

6. Gahring, L., Baltz, M., Pepys, M.B., and Daynes, R. (1984) Proc. Natl. Acad. Sci. U.S.A. 81, 1198-1202.

7. Cybulsky, M.I., Chan, M.K.W., and Movat, H.Z. (1988) Lab. Invest. 58, 365-378.

8. Pettipher, E.R., Higgs, G.A., and Henderson, B. (1986) Proc. Natl. Acad. Sci. U.S.A. 83, 8749-8753.

9. Rubin, R.M. and Rosenbaum, J.T. (1988) Biochem. Biophys. Res. Commun. 154, 429-436.

10. Cavender, D.E., Haskard, D.O., Joseph, B., and Ziff, M. (1986) J. Immunol. 136, 203211 .

11. Pohlman, T.H., Stanness, K.A., Beatty, P.G., Ochs, H.D., and Harlan, J.M. (1986) J. Immunol. 136, 4548-4553.

12. Pober, J.S., Revilacqua, M.P., Mendrick,D.L., Lapierre, L.A., Fiers, W., and Gimbrone, M.A. Jr. (1986) J. Immunol. 136, 1680-1687.

13. Bevilacqua, M.P., Pober, J.S., Mendrick, D.L., Cotran, R.S., and Gimbrone, M.A. Jr. (1987) Proc. Natl. Acad. Sci. U.S.A. 84, 9238-9242.

14. Entman, M.L., Yonker, K., Shappell, S.B., Siegel, C., Rothlein, R., Dreyer, W.J., Schmalstieg, F.C. and Smith, C.W. (1990) J. Clin. Invest. 85, 1497-1506.

15. Strieter, R.M., Kunkel, S.L., Showell, H.J., and Marks, R.M. (1988) Biochem. Biophys. Res. Commun. 156, 1340-1345.

16. Rollins, B.J., Yoshimura, T., Leonard, E.J., and Pober, J.S. (1990) Am. J. Pathol. 136, 1224-1233.

17. Auron, P.E., Webb, A.C., Rosenwasser, L.J., Mulli, S.F., Rich, A., Wolff, S.M. and Dinarello, C.A. (1984) Proc. Natl. Acad. Sci. U.S.A.. 81, 7907-7911.

18. Lomedico, P.T., Gubler, U., Hellman, C.P., Dukovich, M., Giri, J.G., Pan, Y.E., Collier, K., Semionow, R., Chua, O.A., and Mizel, S.B. (1984) Nature 312, 458-462.

19. Johnson, K.J, and Ward, P.A. (1974) J. Clin. Invest. 54, 349-356.

20. Warren, J.S., Yabroff, K.R., Remick, D.G., Kunkel,S.L., Chensue, S.W., Kunkel, R.G., Johnson, K.J., and Ward, P.A. (1989) J. Clin. Invest. 54, 1873-1882. 
21. Mizel, S.B. (1981) In Manual of Macrophage Methodology (H.B. Herscowitz, H.T. Holden, J.A. Bellanti, and A. Ghaffar, Eds.) pp. 329-336. Marcel Dekker, New York, NY.

22. Ruff, M.R., and Gifford, G.E. (1980) J. Immunol. 125, 1671-1677.

23. Warren, J.S., Yabroff, K.R., Mandel, D.M., Johnson, K.J., and Ward, P.A. (1990) Free Rad. Biol. Med. 8, 163-172.

24. Henson, P.M.,Zanolari, B.,Schwartzman, N.A., and Hong, S.R. (1978) J. Immunol. 121, 851-855.

25. Bussolino, F., Comussi, G. and Baglioni, C. (1986) J. Biol. Chem. 263, 11856-11861.

26. Dinarello, C.A., Cannon, J.G., Wolff, S.M., Bernheim, H.A., Beutler, B., Cerami, A., Figari, I.S., Palladino, M.A., and O'Connor, J.V. (1986) J. Exp. Med. 163, 1433-1439.

27. Nawroth, P.P., Bank, I., Handley, D., Cassimeris, J., Chess, L., and Stern, D. (1986) J. Exp. Med. 163, 1361-1370.

28. Linton, M., and Gallo, P.S. (1975) The Practical Statistician: Simplified Handbook of Statistics. pp. 136-218. Brooks-Cole Publishing Co., Monterey, CA. 